\title{
The Impact of Lecture and Interactive Methods on Student's English Competency
}

\author{
https://doi.org/10.3991/ijet.v15i20.16683 \\ Muhamad Suhaimi Taat ${ }^{(凶)}$, Khalid Abdulbaki, Asma Al-Saqqaf \\ Universiti Malaysia Sabah, Kota Kinabalu, Malaysia \\ suhaimidums.edu.my
}

\begin{abstract}
The current research deals with the perceptions of non-native students at a university college in Oman on the use of the lecture and interactive methods in teaching English. The aim is to find out the method which may assist satisfactorily in improving students' English language competency in terms of skills, developing their cognitive abilities and enhancing their personal growth. This study employs the quantitative approach through conducting and analyzing students' questionnaires related to the lecture and interactive methods of teaching. The findings of this research indicate that the interactive methods are highly viewed by students while the lecture is lower. However, weak students incline to the lecture method in contrast to average, good and very good students. The implications of the use of both methods could be extended to the social side of education. Students exchange ideas, suggestions and feelings which contribute to strengthening their relationships as colleagues. They would practice expressing their thoughts freely and respecting the viewpoints of others no matter whether they agree or disagree with them. Consequently, this would have positive impacts on their lifestyle when dealing with their surrounding society and in workplaces in later stages.
\end{abstract}

Keywords - Lecture, Interactive, Method, English, Competency.

\section{Introduction}

Language, nonetheless, is seen as the prime means that is normally used in delivering information to learners. The English language competency has become a prerequisite for admission to many different departments at universities as it is considered the common medium of instruction [1]. Language and literature teaching courses, therefore, have been included in the curricula of many universities around the world. Consequently, the need for researching on the methods of teaching and learning of the English language and literature would be a significant issue [2].

Nowadays, educational systems, among others, have been deeply affected by the wide spread of the information technology inventions as the case for other disciplines. Sources of education for students in different stages have not, therefore, solely envisaged by and limited to an educator, a class or a library. Anyone, anywhere and at any 
time, including students, may have access to a huge volume of diverse types of material exposed immediately to them through the technological media.

The methods of teaching which are used in teaching English in the language classrooms at universities are various [3]. Among the common methods are the lecture method and the interactive method [4]. They have their own advocates and opponents and each school of thought, however, argues for its case supported by reasons and evidence. Lecturers at university may, thus, find themselves in a dilemma over which method of teaching to adopt in the language class to achieve the study outcomes.

Therefore, the methods of teaching, as the basic means of imparting knowledge and information to learners, may have to be carefully selected, modified or even revised [5]. Students, as the prime targets of teaching and learning, would have their own share of tasks in extracting information from different sources, inside or outside the educational institution, in addition to the fundamental roles of teacher and library.

The link between the language and its context assists in improving learning. Linguists and ELT scholars [6] also stress the significance of interaction in the language classroom and argue for the necessity of creating a different teaching approach for the non-native speakers of English. This research study, thus, starts from the premise that there may be an effective, advantageous and favorable method of teaching at university according to the non-native students' perception which could play a decisive role in the teaching and learning process.

\section{Research Objectives}

Accordingly, the aim of this research study is to find out the perceptions and views of a university college students on using the lecture or interactive methods in teaching English at university. The effective method of teaching may assist in achieving the pedagogical goals and objectives of the above-mentioned college. Specifically, the objectives of this research are as follows:

1. This research study aims at finding out the perception of students on the two methods: the lecture and interactive methods of teaching.

2. This research study aims at finding out whether there is any impact of lecture and interactive methods towards students' competence in English.

\subsection{Research hypothesis}

Ho1 There is no significant impact of lecture and interactive methods towards students' competency in English.

\section{The Use of The Lecture Method in Teaching}

Lecturing, as it may be widely known, has been for a long time the main feature of a university life. Also, lecturing is probably considered the teaching method that is frequently used by many higher education staff members in their endeavor to com- 
municate ideas, concepts and knowledge to their recipient students at university [7]. The traditional lecture-based method of teaching has been utilized in college and university classrooms across the world for centuries. This paradigm of teaching, which conforms to behaviorist pedagogy, involves the transfer of a well synthesized body of knowledge from the teacher to the student in a structured manner in a classroom [8]. In this style of teaching, the student is a passive recipient of knowledge. This can result in inattention from students, often distracted from the class environment [9].

Lecturing, however, is not just a matter of standing in front of a class and delivering what the lecturer knows. The classroom lecture, according to [10], is a special form of communication in which voice, gesture, movement, facial expression, and eye contact can either complement or detract from the content. No matter what the lecture topic, the lecturer's delivery and manner of speaking influence students' learning significantly. Lectures, though often criticized for their monolithic instruction style and which are associated with the lack of motivation on the side of the students leading to a very low learning success, are still one of the most efficient educational methods known in higher education. In addition, lectures, are very adaptive to timetables, other courses, different audiences and new cognitions, and they play a valuable part in the social life of the students.

\subsection{Pedagogical aspects of lecture}

A lecture is a straightforward means of communicating knowledge to students. Lecturers would also have a great control over what is being delivered in the classroom since they are the prime source of information. [11] maintains that students who are auditory learners find that lectures appeal to their learning style more than to other students'. Lecturing is mostly easier to be carried out than other methods of teaching [12]. Therefore, the lecture method might be the most familiar and acceptable by many lecturers as it could typically be the method they have grown up with through the span of their life. In addition, the lecture method might be commonly used in teaching as many divergent subjects as human mind could imagine.

In agreement with this claim, [13] postulates that lecturing is still the teaching method that dominates in many universities around the world. Its proportion to all other methods may reach two to one, and sometimes it could be the only method used. Probably, most college teachers lecture. Even those who embrace a modern view of participatory learning still turn to the lecture from time to time. However, a lecture is just one choice in a lecturer's variety of teaching methods. As with all the other choices, it may only be used when they are most appropriate. The lecture method, as [14] state, continues to play a prominent role in the teaching of most disciplines at universities. This is despite persistent and widespread criticism of the lecture as a common teaching method.

Students in a lecture, nevertheless, come from different backgrounds and possess a broad range of skills and abilities. A lecturer at university, thus, as [5] point out, could be expected to combine the talents of scholar, writer, producer, and teacher in ways 
that contribute to student learning. A good lecture always offers a point of view and an avenue of entry into a field of study.

The objective of most lectures, according to [10], is to clarify points in a topic. They may not confuse students or providing them with too much unrelated redundant information. While striving for clarity and concision, a lecturer at university may also try for a relaxed, conversational tone during the lecture.

\section{The Use of the Interactive Method in Teaching}

An Interactive lecture is a method of teaching which aims at creating an interactive engagement in class. In the interactive lectures the lecturer intends to have intervals to include the students to participate in activities that allow them to involve directly with the material [15]. These activities provide students with opportunities to apply what they have learned earlier. Interactive lecturing involves an increased interchange between lecturers, students and the lecture content. The use of interactive lectures can promote active learning, heighten attention and motivation, give feedback to the lecturer and the student, and increase satisfaction for both.

Lectures as it is known play a vital role in teaching. Yet when students engage actively with material, they generally understand it better and remember it longer. Lecturers, thus, may ask for students' participation as this could highlight the distinction between faculty covering material and students' learning it. [16] claims that students' participation often results in covering less material during a semester, but it also means that students learn more material than in a traditional lecture course because they truly grasp the fundamentals and have more chances to clear up confusion.

In all cases, interactive lecturing implies active involvement and participation by the audience so that students are no longer passive in the learning process. Interactive lecturing also implies a different way of approaching the teacher's role. Results of a research on students' experiences of lectures which included many opportunities for active engagement through interactive learning activities indicate that most of students, as [16] states, valued the mix of traditional lecturing and cooperative learning tasks. They particularly enjoy the variety of activities, the opportunities for smallgroup and whole-class discussions, the clear focus on one or two central ideas and the authenticity of the tasks [17].

\subsection{Structure of interactive lecture}

The goal of interactive lecture is to engage students by finding ways for them to interact with the content, the lecturer, and their classmates. Accordingly, interactive lectures include parts of lecture combined with parts where students interact [18]. One of the things that turns the lecture interactive is the ability of the lecturer to focus on the content of the lecture parts that are relevant to the students' needs.

All the activities used to make lectures interactive involve a learning curve for both lecturers and students. Lecturers can use a variety of interactive activities to engage their students in a wide array of contexts and with multiple learning goals. The lectur- 
ers might want to open with some sort of engagement trigger to capture students' attention. As with many active-learning techniques, interactive lectures may take longer to cover any given topic than non-interactive ones. The lecturer saves time by only going over more difficult and important material rather than duplicating the coverage of the textbook. The lecturers must also find a learning task that serves as the centre of the interactive lecture segment.

Making lectures interactive by using techniques that allow all of the students to participate, instead of having individual students answer questions when called on, will promote students' retention and learning of the material presented during lecture. [16] proposes that lecturers may give students practice in developing critical thinking skills and enable lecturers to assess how well the class is learning that day. These activities would allow students to immediately apply content and provide feedback to the lecturer on students. An effective interactive lecture is likely to call upon a blend of various interactive techniques all in one class period [16]. Teaching which seeks to elicit a response from students by questioning or through collaborative problemsolving tasks, can develop deep approaches to learning in which students focus on understanding concepts to relate new ideas to previous knowledge, experiences and themes rather than simply memorizing facts. This experiential learning has a quality of personal involvement.

There are many assumed benefits related to the active student engagement in lectures. Students who contribute enthusiastically to lectures retain information for longer than if they simply see or hear it $[5,19]$. Active learning has also been linked to higher student motivation and increased confidence with class [20]. As it has been said earlier, interactive lecturing can promote active involvement with the material or the content, with the lecturer, or with classmates.

\section{$5 \quad$ Research Methodology}

This research study, therefore, employs survey method since a quantitative approach is one in which the investigatory primarily uses postpositive claim for developing knowledge such as cause and effect thinking, reduction to specific variables and hypotheses and question, use of measurement and observation, and the test of theories, employs strategies of inquiry such as experiment and survey and collect data on predetermined instrument that yield statistics data [21].

The research design for this study employed quantitative collecting techniques to collect data. The research starts with a questionnaire that aims at looking in depth into the students' perceptions of the lecture and interactive methods in teaching English language and literature at university. The set comprises students' questionnaires related to the lecture and interactive methods.

\subsection{Population and sample}

The research population consisted of all third- and fourth-year students who study English language and literature in the Department of English Language and Literature 
at a university college in Oman. The total duration of study for bachelor's degree in this college is four academic years.

For this study, random sampling is used as it is appropriate in this context. In random sampling each member of population is equally likely to be chosen as part of the sample. Random samples are used to avoid bias and other unwanted effects. In this technique, each member of the population has an equal chance of being selected as subject. The sample size of this study is shown in Table 1.

Table 1. Population and sample size (3rd and 4th year students)

\begin{tabular}{|c|c|}
\hline Population & Sample size \\
\hline 310 & 150 \\
\hline
\end{tabular}

\section{$5.2 \quad$ Research instruments}

This research study consists of quantitative data. There are two types of instruments used which are test and questionnaire. Their competence was measured according to a standardized English test results into different levels which are, Weak: 0- 60, Average: 61- 70, Good: 71- 80 and Very good: 85-100. Besides that, the questionnaire papers were distributed to the student respondents and none of the papers was discarded.

In this research, two similar questionnaires, related to the lecture and interactive methods of teaching at university, were duly prepared for students. All the items in these sets of questionnaires were intended to be closed-ended. They were developed by the researchers which were adapted from [22] and [23]. The Likert scale which consists of five levels that start from strongly agree, agree, neutral, disagree to strongly disagree was used in this research study. The research instruments are explained in the Table 2 .

Table 2. The questionnaires categories

\begin{tabular}{|l|l|c|}
\hline \multicolumn{1}{|c|}{ Variables } & \multicolumn{1}{|c|}{ Categories (Constructs) } & Items \\
\hline \multirow{4}{*}{$\begin{array}{l}\text { The Lecture Method } \\
\text { The Interactive Method }\end{array}$} & a. General Preferences & $1-09$ \\
\cline { 2 - 3 } & b. Language Skills & $10-18$ \\
\cline { 2 - 3 } & c. Cognitive Enhancement & $25-30$ \\
\cline { 2 - 3 } & d. Personal Growth & $31-40$ \\
\cline { 2 - 3 } & e. Management of Learning & \\
\hline
\end{tabular}

To test the validity of the items, analysis factor shows that all items are retained because their loading factors are higher than 0.40 [24]. For the internal validity (reliability), all the variables have good result (Cronbach's Alpha=0.891). The reliability analysis is shown in Tables 3. 
Table 3. Reliability analysis

\begin{tabular}{|l|c|c|}
\hline \multicolumn{1}{|c|}{ Categories (Constructs) } & Item & Cronbach Alpha \\
\hline a. General Preferences & $1-9$ & 0.730 \\
\hline b. Language Skills & $10-18$ & 0.701 \\
\hline c. Cognitive Enhancement & $19-24$ & 0.792 \\
\hline d. Personal Growth & $25-30$ & 0.744 \\
\hline e. Management of Learning & $31-40$ & 0.780 \\
\hline Total & $1-40$ & 0.891 \\
\hline
\end{tabular}

Before the analysis for inferential statistic (multiple regression) to test the hypothesis can be employed, the data for all the variables must be normally distributed. The normality test using skewness and kurtosis shows that all the variables are normally distributed. The value of skewness and kurtosis for all the variables show the accepted values for normality which ranges between -1 to +1 [24]. Therefore, the inferential statistics to test the hypothesis can be employed. The analysis of the skewness and kurtosis for all the variables in this study can be referred to Table 4.

Table 4. Normality Analysis

\begin{tabular}{|l|l|c|}
\hline \multirow{4}{*}{ Lecture } & \multicolumn{1}{|c|}{ Mean } & $\mathbf{2 . 9 2}$ \\
\cline { 2 - 3 } & Std. Deviation & .374 \\
\cline { 2 - 3 } & Skewness & .671 \\
\cline { 2 - 3 } Interactive & Kurtosis & .245 \\
\hline \multirow{5}{*}{ Competency } & Mean & 3.59 \\
\cline { 2 - 3 } & Std. Deviation & .402 \\
\cline { 2 - 3 } & Skewness & -.441 \\
\cline { 2 - 3 } & Kurtosis & .078 \\
\hline & Mean & 66.38 \\
\cline { 2 - 3 } & Std. Deviation & 19.60 \\
\cline { 2 - 3 } & Skewness & -1.001 \\
\cline { 2 - 3 } & Kurtosis & -.183 \\
\hline
\end{tabular}

\section{$6 \quad$ Findings}

6.1 What is the perception of students on the two methods: Lecture and interactive?

What is the perception of students on the lecture method in terms of General Preferences (GP), Improvement of Language Skills (LS), Cognitive Enhancement (CE), Personal Growth (PG) and Management of Learning (ML)?

To answer this question, the means and standard deviations for each category in the independent variable, which is the lecture method, were statistically calculated as shown in Table 5. 
Table 5. Descriptive statistics of the lecture method

\begin{tabular}{|l|c|c|c|l|}
\hline & N & Mean & Std. Deviation & \multicolumn{1}{|c|}{ Level } \\
\hline Mean GP & 150 & 3.06 & 0.32 & Medium \\
\hline Mean ML & 150 & 3.06 & 0.53 & Medium \\
\hline Mean PG & 150 & 2.85 & 0.61 & Medium \\
\hline Mean CE & 150 & 2.80 & 0.60 & Medium \\
\hline Mean LS & 150 & 2.73 & 0.71 & Medium \\
\hline \multicolumn{2}{|l|}{ Total } & 2.91 & 0.55 & Medium \\
\hline
\end{tabular}

Indicators: 1.00-2.33 (Low), 2.34-3.67 (Medium), 3.67-5 (High)

The results in Table 6 indicate that the mean for lecture General preferences (GP) has the highest mean comparing to the means of other categories as it reaches (3.0630) with moderate level according to the criteria of classifications of means. Meanwhile, the mean lecture Language skills (LS) obtains the lowest mean (2.7341)

What is the perception of students on the interactive method in terms of General Preferences (GP), Improvement of Language Skills (LS), Cognitive Enhancement (CE), Personal Growth (PG) and Management of Learning (ML)?

To answer this question, the means and standard deviations for each category in the independent variable, which is the interactive method, were statistically calculated as shown in Table 6.

Table 6. Descriptive statistics of the interactive method

\begin{tabular}{|l|c|c|c|l|}
\hline & $\mathbf{N}$ & Mean & Std. Deviation & \multicolumn{1}{|c|}{ Level } \\
\hline Mean LS & 150 & 3.89 & 0.69 & Medium \\
\hline Mean PG & 150 & 3.69 & 0.61 & Medium \\
\hline Mean CE & 150 & 3.59 & 0.69 & Medium \\
\hline Mean ML & 150 & 3.49 & 0.37 & Medium \\
\hline Mean GP & 150 & 3.34 & 0.39 & Medium \\
\hline Total & 3.59 & 0.55 & Medium \\
\hline
\end{tabular}

Indicators: 1.00-2.33 (Low), 2.34-3.67 (Medium), 3.67-5 (High)

The results in table 7 indicate that the mean interactive Language skills (LS) has the highest mean comparing to the means of other categories as it reaches (3.89) with highly important level according to the criteria of classifications of means. Meanwhile, the mean interactive General preference (GP) obtains the lowest mean (3.34) as it is at a moderate level according to the criteria.

Is there is any impact of lecture and interactive methods towards students' competency in English?

Multiple regression analysis was carried out to test this hypothesis:

Ho7 There is no significant influence of lecture, discussion and interactive methods towards students' competence in English.

The finding as shown at Table 7 shows that there is significant impact of lecture method towards competence in English ( $\mathrm{R} 2=.140$, Sig.=0.000), interactive method is excluded from the model which indicates that it is not significantly influencing the dependent variable (sig.>0.05). Since there is significant influence of at least one 
independent variable which is lecture method towards students' competencies, therefore, Hol is rejected.

Table 7. Stepwise Regression analysis

\begin{tabular}{|l|c|c|c|c|c|c|}
\hline Predictor variable & B & T & P (Sig.) & $\mathbf{R}^{\mathbf{2}}$ & Beta $(\boldsymbol{\beta})$ & F \\
\hline Lecture method & -19.607 & -4.892 & .000 & 0.140 & -0.374 & 23.935 \\
\hline
\end{tabular}

Based on the Table 7, the values for B and significant for lecture method as the predictor variable indicates that when the lecture method increases one unit, students' competency as criterion variable will be decreased 19.61 unit $(\beta=-0.374, \mathrm{t}=-4.892$, $\mathrm{p}<0.05)$. The finding reveals that the lecture method contributes $14 \%(\mathrm{R} 2=0.140$ ) towards students' competency. Therefore, there is $84 \%$ change in the criterion variable which cannot be explained or predicted in this study due to other factors which were not included in this study. Since the significant value is less than 0.05 , the null hypothesis (Ho1) is rejected. Therefore, lecture method has significant negative impact on the student's English competency which means that the higher usage of lecture method will lower the competency of the students.

\section{$7 \quad$ Discussion}

To discuss the findings of question one, it is noticed that students' perception of the lecture method regarding the category general preferences (GP) has shown the highest mean comparing to the means of other categories as it reached a neutral level.

This may be due to the fact that the lecture method involves the lecturer taking the lead in delivering knowledge with minimum or no participation of the students [5]. Thus, students become dependent on the lecturer to tell them what they need to know and can avoid taking responsibility for their own learning [20]. Some students benefit from the lecture and incline to listen to the lecturer since he is the main source of knowledge for them.

On the other hand, the category language skills (LS) obtains the lowest mean since students believe that they are unable to listen to others' opinions while taking notes, unable to ask as well as answering questions during the lecture, unable to make an oral summary of the topic of lecture, unable to give short talk on the topic of the lecture, unable to express their ideas which can be understood by others, and do not feel their fluency develops by the lecture method. However, they agreed that their pronunciation improves by the lecture method, their command of the English grammar improves through lecturing and their vocabulary increases by lecturing.

Although some student respondents agreed that certain language skills such as pronunciation, grammar and vocabulary can be improved by the lecture method, the lecture method, according to some scholars [25], could be less effective in developing students' independent higher-order thinking abilities. Research findings, thus, suggest that while the traditional lecture can be applied to communicate information in a limited period, it could not be used effectively by itself to develop ideas or to alter attitudes [26]. 
Regarding the perception of students on the interactive method, it is seen that the mean interactive Language skills (LS) has the highest mean comparing to the means of other categories with highly important level according to the criteria of classifications of means. Meanwhile, the mean interactive General preference (GP) obtains the lowest mean as it is at a neutral level according to the criteria.

Students believe that during the interactive method, they develop their language skills as they are able to listen to others' opinions while taking notes, able to ask as well as answering questions during the interactive lecture, able to make an oral summary of the topic of interactive lecture, able to give short talk on the topic of the interactive lecture, able to express ideas which can be understood by others, feel their fluency develops by the interactive method, their pronunciation improves by the interactive method, their command of the English grammar improves through interactive lecturing and their vocabulary increases by the use of interactive lecturing. Moreover, interactive lectures could comprise components of the lecture which are related to the parts where students interact. Among the ways that turn the lecture into an interactive one is the ability of the lecturer to select the content of the lecture parts in accordance with the students' needs.

Meanwhile, the mean interactive general preference (GP) obtains the lowest mean as it is at a neutral level according to the criteria. Nevertheless, some student respondents stress the role of lecturers in their learning. Interactive lecturing involves an increased interchange between lecturer, students and the lecture content. The use of interactive lectures can promote active learning, heighten attention and motivation, give feedback to the lecturer and the student, and increase satisfaction for both [27]. It could also refer to a verbal discussion among the participants such as students' indulgence with the material or the content of a lecture, but it does not necessarily mean that students have to do all of the talking. It involves the students by encouraging them to interact with content, the lecturer, and their colleagues [28].

As for the multiple regression analysis to look at the impact of the lecture and interactive method on the English competency, the finding shows that there is significant influence of lecture method towards competence in English, with interactive method are excluded from the model which indicates that it is significantly influencing the dependent variable. The reasons for this influence could be that the lecture method provides students with knowledge related to exams otherwise they are unable to obtain. The lecture is also good for auditory learners and those who are aware of different modes of presentation especially students whose first language is not English [29].

The influence of students' perception of the methods on students' levels could also be explained through relying on one of the approaches to study namely the strategic or achieving approach. Here the emphasis is on organizing learning specifically to obtain a high examination grade. With this intention, a learner who often uses a deep approach may adopt some of the techniques of a surface approach to meet the requirements of a specific activity such as test. The achieving approach is intimately associated with assessment [12]. 


\section{Conclusion}

In conclusion, it would not be unusual to state the simple fact that effective teaching would expectedly lead to positive learning. The methods of teaching at university chosen by lecturers could have a great impact on the outcomes that would be eventually achieved by students at the end of a course. Lecturers, therefore, may bear a huge ethical responsibility towards their students and themselves. As the lecture method is an old and traditional way for delivering knowledge, it has been used successively by many generations of teachers and scholars throughout the centuries. It would not be easy to lose ground and be challenged by another method of teaching. The research has shown that the lecture method is still preferred by some students especially the weak ones in teaching at university. The study has also indicated that the majority of students lean towards interactive methods in teaching English. The interactive method has been favoured by students as they believe that they are not only passive recipients of knowledge, who are constantly in the position of the listeners but, with assistance of the lecturer, are actively involved in the lecturing process to get maximum knowledge. As a result, the information received in class would be remembered for a longer time. Finally, the findings of the present research study have demonstrated the students' tendency towards the use of the interactive methods in teaching and learning. These methods could replace or be used along with the traditional lecture method which definitely comprises certain positive aspects.

\section{References}

[1] Doiz, A., Lasagabaster, D. \& Sierra, J. (eds.). (2012). English-medium instruction at universities: Global challenges. Bristol: Multilingual Matters. https://doi.org/10.21832/9781 847698162

[2] Gutiérrez, D. C. \& Villegas, E. G. (2015). The importance of teaching methodology in higher education: A critical look. Procedia- Social and Behavioral Sciences, 17(4), 377382. https://doi.org/10.1016/j.sbspro.2015.01.677

[3] Siddig, B.E. (2020). Social Media in Teaching of Languages. International Journal of Emerging Technologies in Learning. 15(12), 72-80. https://doi.org/10.3991/ijet.v15i12.126 $\underline{45}$

[4] Creemers, B. \& Kyriakides, L. (2011). Improving quality in education: Dynamic approaches to school improvement. London: Routledge.

[5] Fry, H., Ketteridge, S. \& Marshall, S. (2009). A handbook for teaching and learning in higher education: enhancing academic learning. London: Routledge Falmer. https://doi. org/10.4324/9780203891414

[6] Taat, M.S., Francis, A. (2020). Factors influencing the students' acceptance of e-learning at teacher education institute: An exploratory study in Malaysia. International Journal of Higher Education. 9 (1), 133-141. https://doi.org/10.5430/ijhe.v9n1p133

[7] Charlton, B.G. (2006). Lectures are an effective teaching method because they exploit human evolved 'human nature' to improve learning - Editorial. Medical Hypotheses, 67, 1261-5. https://doi.org/10.1016/j.mehy.2006.08.001 
[8] Kamardeen, I. (2014). Adaptive e-Tutorial for Enhancing Student Learning in Construction Education. International Journal of Construction Education and Research, 10(2), 7995. https://doi.org/10.1080/15578771.2012.756437

[9] Corporan, R.A., Nagata, J.J., Garcia, A.V.M. (2020). Perception of Teachers on Collaborative Tools Knowledge Level Mediated by ICT and Their Experience with Students. International Journal of Emerging Technologies in Learning. 15(11), 137-160. https://doi.org/ 10.3991/ijet.v15i11.13121

[10] Davis, B. G. (2009). Tools for teaching. San Francisco, California: Jossey-Bass.

[11] Huxham, M. (2005). Learning in lectures. Active Learning in Higher Education, 6: 17-31. DOI: $10.1177 \% 2$ F1469787405049943

[12] Ramsden, P. (2003). Learning to teach in higher education. London: Routledge.

[13] Bligh, D. (2001). What's the Use of Lectures? San Francisco: Jossey-Bass.

[14] Hart, S., Dixon, A., Drummond, M.J. \& McIntyre, D. (2004). Learning without Limits. Maidenhead: Open University Press.

[15] Stanley, C., \& Porter, E. (Eds.). (2002). Engaging large classes: Strategies and techniques for college faculty. Bolton, MA: Anker Publishing Company.

[16] Cavanagh, M. (2011). Students' experiences of active engagement through cooperative learning activities in lectures. Active Learning in Higher Education. https://doi.org/10.11 77/1469787410387724

[17] Charlie, E.F., Taat. M.S., Saikim, F.H. (2017). Students' Interpretation and Commitment of Conservation Contents Based on School Context. Advanced Science Letters. 23 (4), 2704-2708. https://doi.org/10.1166/asl.2017.7701

[18] Morgan, D. L. (2007). Paradigms lost and pragmatism regained: Methodological implications of combining qualitative and quantitative methods. Journal of Mixed Methods Research, 1(1), 48-76. https://doi.org/10.1177/2345678906292462

[19] Setyarini, T.A., Mustaji, Jannah, M. (2020). The Effect of Project-Based Learning Assisted PANGTUS on Creative Thinking Ability in Higher Education. International Journal of Emerging Technologies in Learning. 15(11), 245-251. https://doi.org/10.3991/ijet.v15i11. $\underline{12717}$

[20] Machemer, P. \& Crawford, P., (2007). Student perceptions of active learning in a large cross disciplinary classroom. Active Learning in Higher Education, 8(1), pp. 9-30. https:// doi.org/10.1177/1469787407074008

[21] Creswell, J. (2014). Research Design: Qualitative, Quantitative, and Mixed Methods Approaches. (4th ed.). Los Angeles, CA: Sage.

[22] Cook, V. (2001). Second language learning and language teaching. (3rd Edition). New York: OUP Inc.

[23] Moreno-Murcia, J., Torregrosa, Y. \& Pedreño, N. (2015). Questionnaire evaluating teaching competencies in the university environment. New Approaches in Educational Research, 4(1), 54-61. https://doi.org/10.7821/naer.2015.1.106

[24] Hair, J.F, Black, W.C., Babin, B.J., Anderson, R.E. (2013). Multivariate Data Anlysis. (7 ${ }^{\text {th }}$ Edition). United Kingdom: Pearson Education Limited

[25] McKeachie, W. J., \& Svinicki, M. (2006). McKeachie's teaching tips: Strategies, research, and theory for college and university teachers (12th Ed.). Boston: HoughtonMifflin.

[26] Ndebele, C. \& Maphosa C. (2013). Promoting active learning in large class university teaching: Prospects and challenges. Journal of Social Sciences, 35(3), 251-262. https://doi. org/10.1080/09718923.2013.11893164

[27] Blumberg, P. (2008). Developing learner-centered teachers: A practical guide for faculty. San Francisco: Jossey-Bass. 
[28] Abdulbaki, K., Suhaimi, M., Alsaqqaf, A., Jawad, W. (2018). The use of the discussion method at university: Enhancement of teaching and learning. International Journal of Higher Education. 7(6), 118-128. https://doi.org/10.5430/ijhe.v7n6p118

[29] Wood, L.N., Sadhbh, J., Petocz, P. \& Rodd, M. (2007). Learning in lectures: multiple representations. International Journal of Mathematical Education in Science and Technology. 38(97), 907-915. DOI: 10.1080/00207390701561496

\section{Authors}

Muhamad Suhaimi Taat is an Associate Professor at the Faculty of Psychology and Education, University Malaysia Sabah. His research interest is in the field of pedagogy, educational sociology, teacher education, administration etc. He has published more than one hundred articles in journals, book chapters, conference papers and newspapers.

Khalid Abdulbaki is currently a PhD candidate at the Faculty of Psychology and Education, University Malaysia Sabah. He was a senior lecturer at a university college in Oman. He taught English for the undergraduate students. He already presented papers related to his study at several international conferences such as in Vienna and the USA.

Asma Al-Saqqaf is a senior lecturer ( $\mathrm{PhD}$ holder) at the Faculty of Psychology and Education, University Malaysia Sabah. She is currently the head of Teaching English as Second Language (TESL) postgraduate program. She collaborates with other disciplines in doing research such as teacher education. She is also editor for faculty's and university's journal.

Article submitted 2020-06-28. Resubmitted 2020-07-23. Final acceptance 2020-07-23. Final version published as submitted by the authors. 